\title{
Orbital malignant peripheral nerve sheath tumours
}

\author{
CHRISTOPHER J LYONS,' ALAN A McNAB,' ALEC GARNER, \\ AND JOHN E WRIGHT' \\ From the 'Orbital clinic, Moorfields Eye Hospital, City Road, London EC1V 2PD, and the ${ }^{2}$ Department of \\ Pathology, Institute of Ophthalmology, London EC1V 9AT
}

SUMmaRY We describe three patients with malignant peripheral nerve tumours in the orbit and review the existing literature on these rare lesions.

\begin{abstract}
Malignant peripheral nerve sheath tumours are unusual in any part of the body and very rare in the orbit, where only 13 cases have previously been described. These tumours can spread rapidly along the involved nerve to the middle cranial fossa. They are radioresistant, and total surgical excision offers the only hope of cure. Our experience with three patients may help clinicians to recognise these lesions and excise them at an early stage.
\end{abstract}

\section{Case reports}

\section{PATIENT 1}

Four years prior to presentation a 55-year-old man noted a small lump at the medial end of his right lower eyelid. This was removed through the palpebral conjunctiva but recurred within a month. A histopathological report was not obtained.

Over the next two years three further attempts were made to remove this lump surgically with either incomplete removal or early recurrence on each occasion. After three years the lump had extended into the floor of the orbit, and a further attempt at excision was made, by a transantral approach.

Histopathological examination on these occasions showed the features of 'a neurofibroma with schwannian transformation in certain areas'. There was no evidence of malignancy. Despite tumour-free resection margins the mass recurred in the floor of the orbit.

At presentation the right vision was reduced to perception of hand movements. The globe was proptosed $5 \mathrm{~mm}$ and displaced inferiorly $6 \mathrm{~mm}$ and laterally $9 \mathrm{~mm}$. There was a marked right relative afferent pupillary defect with disc swelling, and movement of the eye was severely restricted.

Correspondence to Mr C J Lyons, FRCS.
Sensation was diminished over the distribution of the second division of the right trigeminal nerve. The left globe was normal. Plain anteroposterior skull $x$-rays showed a normal appearance, but undertilted occipitomental tomographic views revealed enlargement of the right infraorbital canal (Fig. 1).

An inferior orbital margin incision revealed tumour protruding from the infraorbital foramen and extending beneath the soft tissues of the cheek. The tumour had a firm consistency and a pale grey cut surface. The orbital periosteum on the floor of the orbit was elevated and a mass over $18 \mathrm{~mm}$ in diameter was found within an expanded infraorbital canal which extended posteriorly into the superior orbital fissure. Biopsy specimens were taken.

\section{Histology}

The tumour was composed of a homogeneous and densely packed proliferation of spindle shaped cells aligned in more or less parallel bundles and sheets. In places there was a fascicular pattern with palisading of nuclei, characteristic of Antoni A morphology of a schwannoma (Fig. 2a, b). Looser myxoid areas of Antoni B differentiation were not seen. However, small clear spaces or vacuoles were common, and in some instances the tumour cells were grouped round such spaces to create a pseudoglandular appearance. The reaction for S-100 protein was strongly positive, virtually all the cells being stained (Fig. 2c). The tumour cells had prominent and sometimes multiple nucleoli, were frequently hyperchromatic, and mitotic figures could occasionally be recognised. Scattered giant nuclei were also present. There was no clearly defined capsule, and tumour cells appeared to be infiltrating the adjacent orbital connective tissue. Some haemosiderin resulting from previous haemorrhage was also seen.

Transmission electron microscopy of formalin 


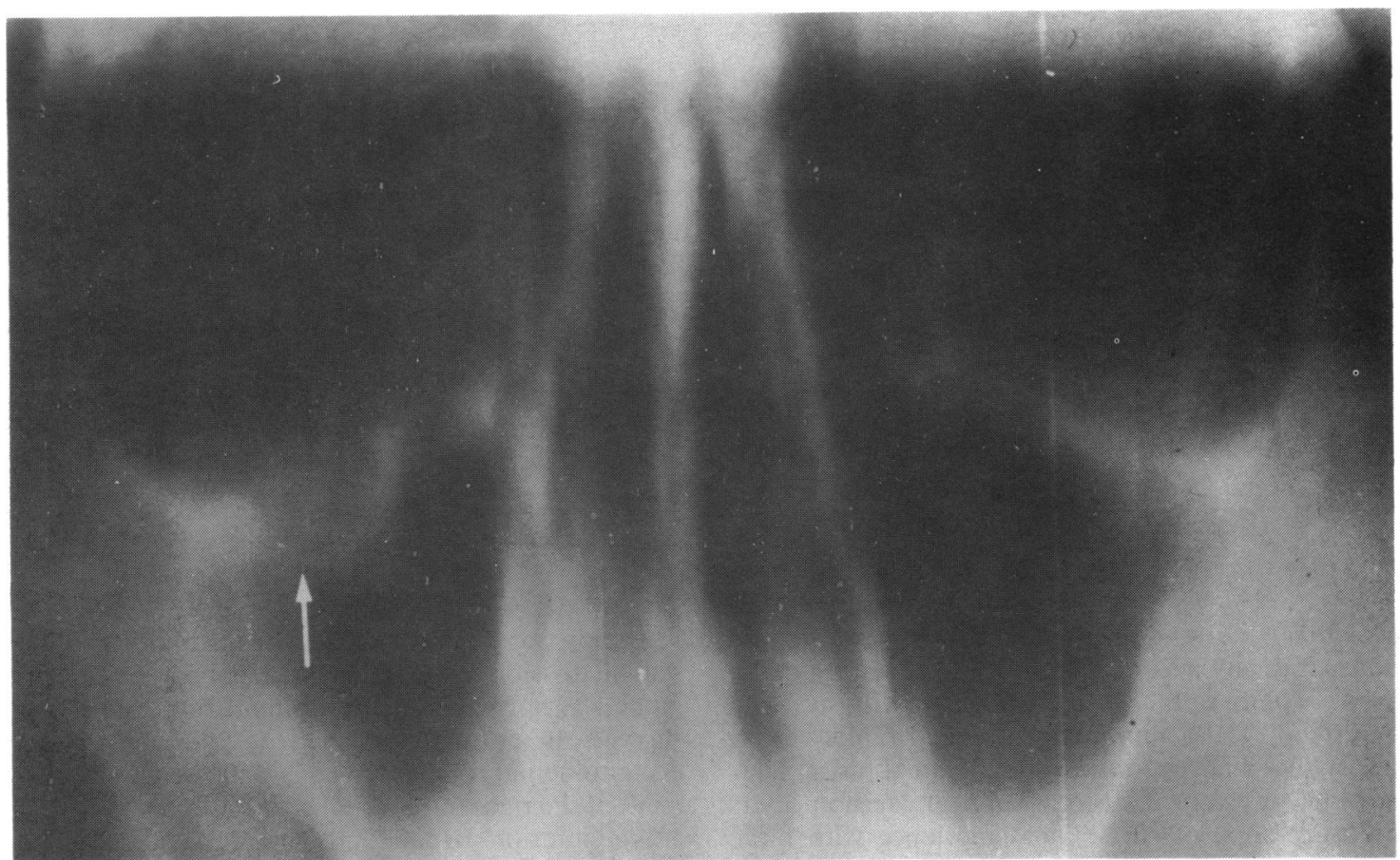

Fig. 1 Patient 1. An undertilted occipitomental tomogram shows enlargement of the infraorbital canal caused by tumour (arrow).

fixed tissue revealed cells with grooved or indented nuclei and conspicuous nucleoli. Individual cells were sometimes linked by complexes resembling desmosomes, and there was incomplete basal lamina formation surrounding the cytoplasmic membranes of occasional cells (Fig. 3). Although rare collagen fibres presented exceptionally prominent crossstriations, long-spacing fibres were not identified. A prominent rough-surfaced endoplasmic reticulum was observed in a minority of cells.

The patient was referred for neuroradiological and neurosurgical opinion to determine if the tumour was resectable. The presence of a large mass in the posterior fossa, continuous with the mass in the orbital floor, was confirmed.

By this time, the patient had developed severe paroxysms of lancinating electric shock-like pain involving the whole of the right side of his face and numbness affecting the left side of his body. He had also noticed voice changes and difficulty in swallowing, and he complained of poor balance and difficulty in walking, with a tendency to fall to the right. Palliative radiotherapy was given. The patient died within four months.

PATIENT 2

A 42-year-old man had noticed discomfort round the left eye and dilated conjunctival blood vessels for eight months. Two months after the onset of these symptoms he had noticed that the left globe was protuberant, and a week before presentation his vision had deteriorated.

At his first attendance his right visual acuity was $6 / 5$ while the left corrected acuity was $6 / 24$. There was a left relative afferent pupillary defect, and the left globe was proptosed $8 \mathrm{~mm}$ axially. Ocular movements were restricted in all directions, especially elevation. Facial and corneal sensation was normal.

The left conjunctiva and episclera were markedly hypervascular, but there was no pulsation nor any audible bruit. The disc was swollen.

A CT scan (Fig. 4) showed a large, well defined, rounded and homogeneous mass situated superiorly within the intraconal space. This enhanced with contrast. An intra-arterial digital subtraction angiogram showed a brisk tumour circulation with early filling by contrast (Fig. 5). The provisional diagnosis was haemangiopericytoma.

At lateral orbitotomy a large firm tumour lying intraconally was dissected free of adjacent structures and found to extend to the superior orbital fissure, where it was transected and its stump subjected to diathermy. Postoperatively the visual acuity remained unchanged. One year after the operation, 

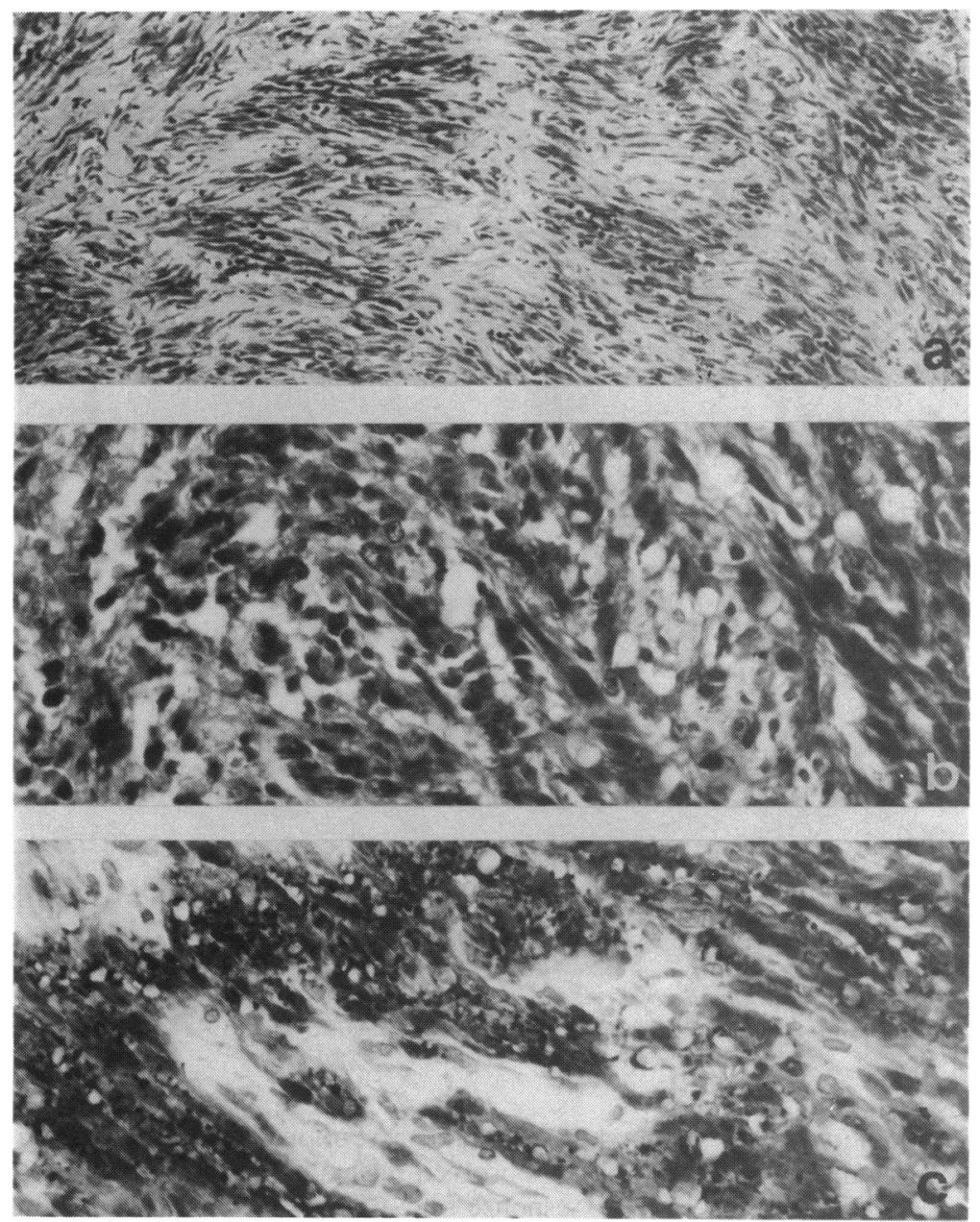

Fig. 2 Patient 1. (a) Cells with elongated, wavy nuclei showing a tendency to a palisade alignment; the histology of the tumour recalls the Antoni A structure typical of schwannoma. (Haematoxylin and eosin, $\times 125$.) (b) In places the tumour cells have abnormally large, hyperchromatic and pleomorphic nuclei and are suggestive of malignancy.

(Haematoxylin and eosin, $\times 313$.)

(c) There is a conspicuous staining reaction for $S$ - 100 protein.

(Immunoperoxidase, $\times 125$.) there was no evidence of local recurrence or distant metastasis.

\section{Histology}

Examination of the tumour revealed a highly cellular neoplasm with a predominance of spindle cell forms. In many areas the cells were grouped in fascicles with a rudimentary attempt at a palisade arrangement (Fig. 6a). Other cells were vacuolated, and there was widespread focal lymphocytic infiltration. Lymphoid tissue was also prominent in the compressed connective tissue which partly encompassed the tumour. Some cells had unusually large, pleomorphic, and hyperchromatic nuclei, and many had conspicuous nucleoli, while occasional mitotic figures were also seen (Fig. 6b). Staining for S-100 protein was observed in scattered tumour cells (Fig. 6c). A few myelinated nerve bundles were present in the tissue surrounding the tumour.
Electron microscopy of a separate piece of the tumour failed to provide any evidence of basal lamina formation round the cells or of long-spacing collagen, though the cytoplasmic processes of the cells showed considerable interdigitation.

\section{PATIENT 3}

A 21-year-old man had noticed a progressively enlarging painless lump in the medial part of his left upper eyelid for five years. Two previous attempts at surgical excision had failed. The visual acuity was $6 / 6$ in each eye. The left globe was proptosed by $6 \mathrm{~mm}$ and displaced laterally by $8 \mathrm{~mm}$. A large mass of soft, almost fluctuant consistency occupied both inner quadrants of the left orbit. There were two surgical scars overlying the mass in the upper lid. CT scans (Fig. 7) revealed an extensive soft tissue mass extending from the skin anteriorly to the posterior limit of the orbit. The orbit was enlarged, and the 


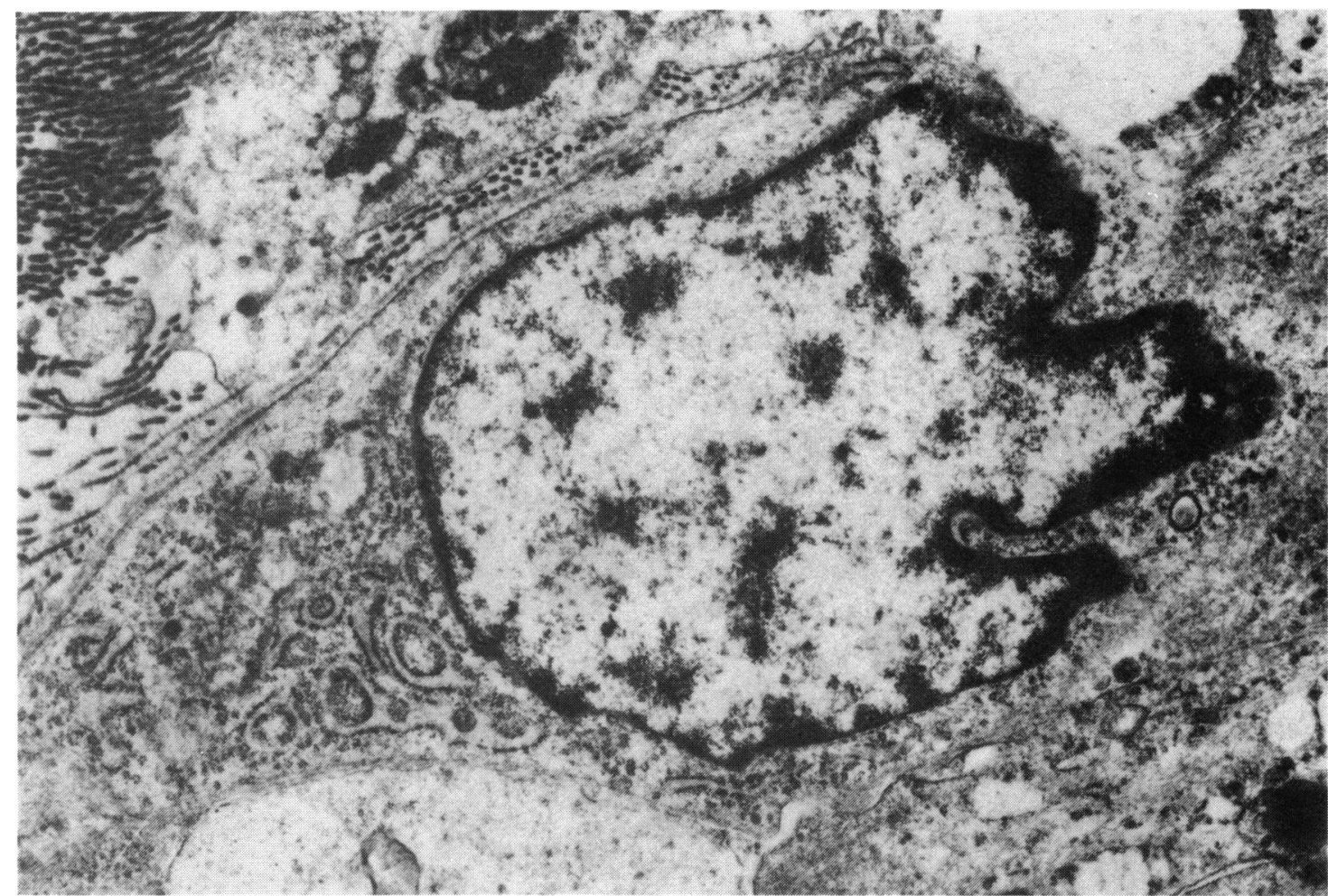

Fig. 3 Patient 1. Transmission electron micrograph showing part of a cell with an indented nucleus and prominent rough endoplasmic reticulum. There is a distinct basal lamina next to the cell surface. (Uranyl acetatellead citrate, $\times 13300$ ).

mass displaced the medial rectus, optic nerve, and globe laterally. The medial wall of the orbit was intact.

At anterior orbitotomy a large tumour was adherent to the orbital septum and trochlea, and the optic nerve posteriorly. Most of the tumour was removed, but a small part remained in the posterior orbit attached to the optic nerve.

Postoperatively the patient retained $6 / 6$ vision but had limited extraocular movements. Histopathological examination showed the tumour to be a malignant peripheral nerve sheath tumour. Exenteration was advised, but the patient refused and was lost to follow-up.

\section{Histology}

The tumour was composed of spindle shaped cells with round, oval, or elongated wavy nuclei and fibrillary cytoplasmic processes (Fig. 8a). The overall structure of much of the tumour was loose, with accumulation of mucoid material and prominent vascularity, but collagen formation was sparse. In some areas there was increased cellularity, a proportion of the cells being pleomorphic with enlarged, hyperchromatic and, exceptionally, multiple nuclei and readily observed nucleoli (Fig. 8b). A positive staining response for S-100 protein was obtained in respect of only a very few cells (Fig. 8c), though the technique served to demonstrate occasional small myelinated nerve bundles within the substance of the tumour. Scattered mast cells were detected. There was some evidence of a capsule in places, but for the most part the tumour had ill-defined margins and appeared to be infiltrating the orbital connective tissue.

\section{Discussion}

HISTOPATHOLOGY

The criteria for recognising malignant peripheral nerve sheath tumours are not fully determined, though the advent of electron microscopical and immunohistochemical techniques has put the diagnosis on rather more certain ground. Consequently reports of such lesions prior to the introduction of these supplementary methods of examination need to be treated with some caution. Four cases diagnosed on conventional histological grounds alone are 


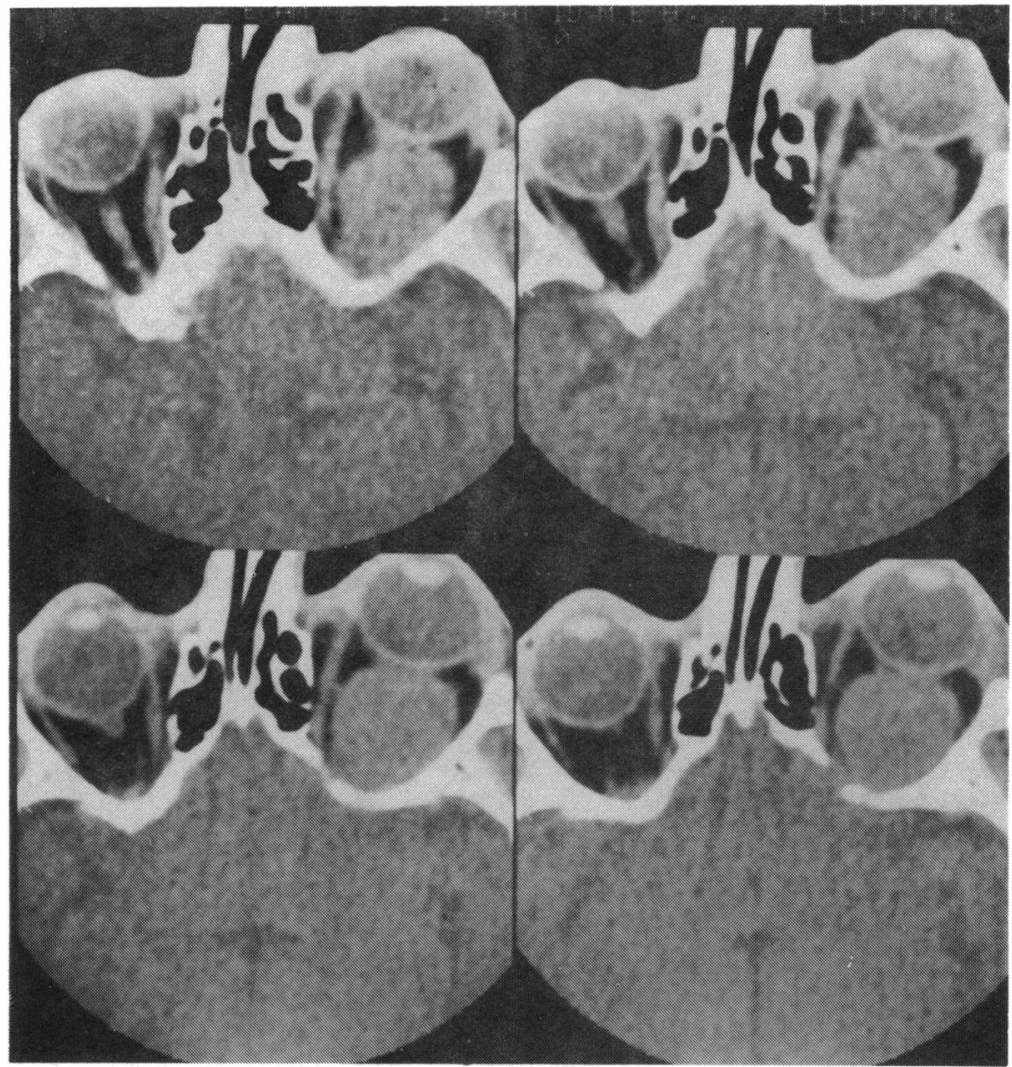

Fig. 4 Patient 2. Axial CT scans with contrast medium show a large well defined and homogeneous intraconal mass extending to the orbital apex.

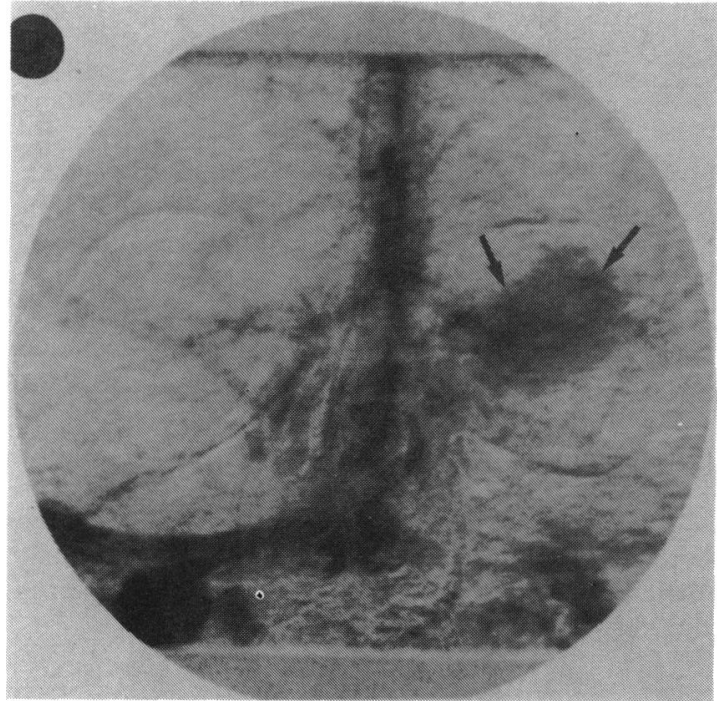

Fig. 5 Patient 2. A digital subtraction angiogram shows a distinct tumour blush within the left orbit (arrows). The tumour filled with contrast early in the arterial phase. probably acceptable, ${ }^{1-3}$ and another case was included in a review by Henderson in $1980,{ }^{4}$ but the best documented series from a pathological point of view are the eight cases reported by Jakobiec et al. in 1985. ${ }^{5}$

All the reported cases including ours have been adults, with an age range of 19 to 76 years.

Because it is possible that some malignant tumours arise from the perineural cell or endoneural fibroblast components of peripheral nerves rather than Schwann cells, there is reason to avoid a terminology which specifies the cell of origin unless this is certainly known. Hence the broader designation of malignant peripheral nerve sheath tumour is preferable to denote the type of neoplasm we have described.

There would seem to be adequate evidence to regard at least two of the present cases as having a primarily schwannian histogenesis. Cases 1 and 2 had an easily identified Antoni A palisade arrangement and gave positive responses for S-100 protein. While the latter is not peculiar to Schwann cells or, possibly, even cells of neural crest origin, its presence in the 
Fig. 6 Patient 2. (a) Part of the tumour showing fascicles of spindle cells arranged in a roughly palisade manner. (Haematoxylin and eosin, $\times 125$ ). (b) Other parts of the tumour are composed of generally pleomorphic cells with vacuolated cytoplasm and occasionally giant nuclei. (Haematoxylin and eosin, $\times 313$ ). (c) Scattered cells give a positive reaction for $S-100$ protein. (Immunoperoxidase, $\times 125$ ).
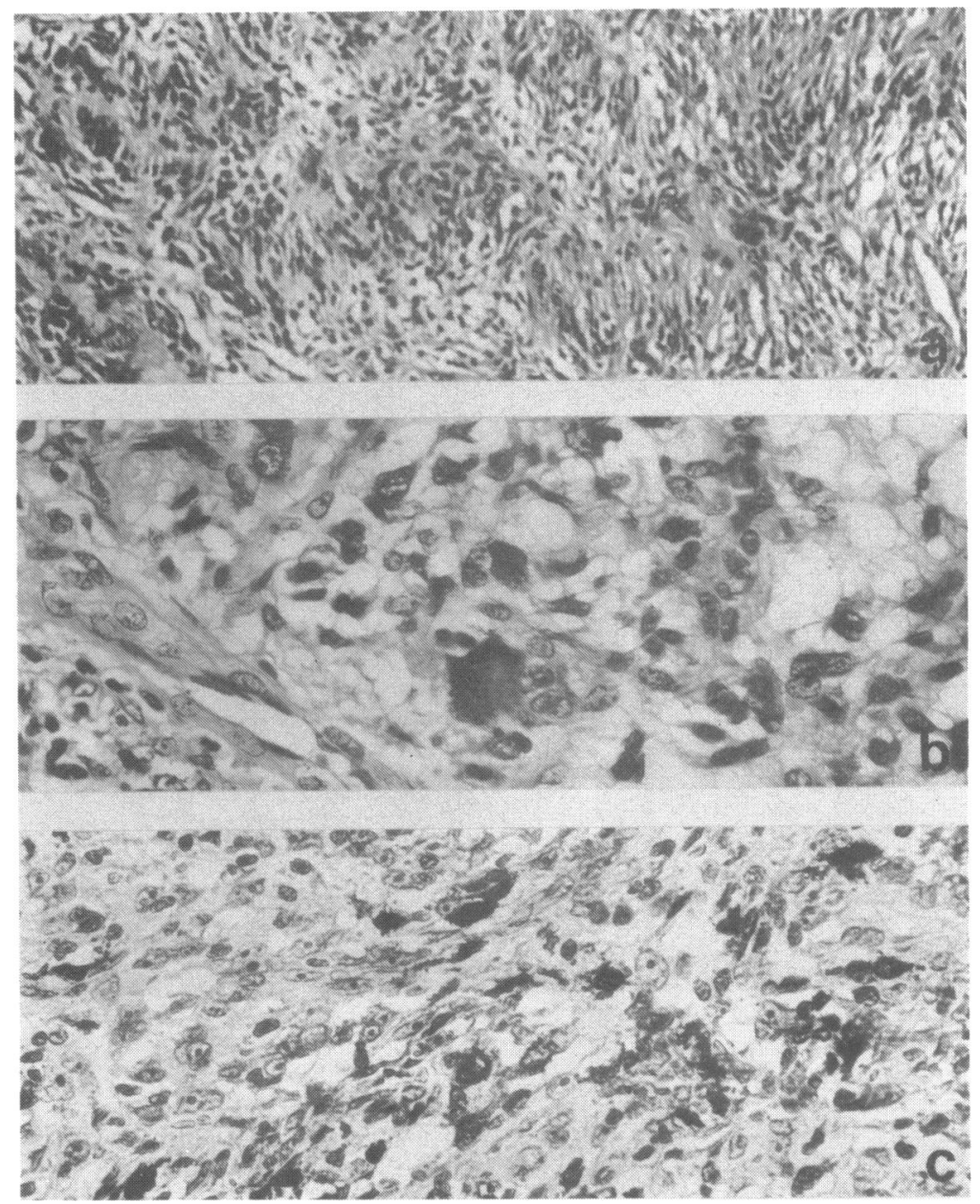

context of spindle cell orbital tumours strongly supports the diagnosis of schwannoma. ${ }^{67}$ Neither fibroblasts nor smooth-muscle cells stain for S-100 protein. The demonstration of a basal lamina surrounding some cells in the first case is also typical of a schwannoma. ${ }^{89}$ Additional features of tumours of schwannian type include pseudomesaxon formation and bundles of long-spacing collagen, but neither was observed in the cases under review. The precise identification of case 3 is less certain, though the finding of cells with elongated wavy nuclei and a frequently myxoid background equivalent to the Antoni B structure associated with schwannomas is in agreement with a peripheral nerve sheath tumour.

The diagnosis of malignancy was based on the presence of cells showing irregularity of size and shape, nuclear enlargement, and hyperchromatism. Mitoses, though seen in each of the three cases, are not a reliable guide to malignancy, and, as others have commented, ${ }^{\text {x }}$ care must be taken not to mistake the hypercellular variant of a benign schwannoma in which there is an almost exclusively Antoni A pattern, so-called cellular neurilemoma, for a malignant lesion. The latter consideration was particularly relevant in respect of case 1 , but in that instance the clinical course provided more than sufficient corroboration of the histological diagnosis. Absence of a capsule and a clearly defined, smooth tumour surface was noted in all three cases and was taken as evidence of an invasive property. Electron microscopy in respect of cases 1 and 2 revealed prominent nucleoli in many tumour cells, and this also is suggestive of malignancy.

\section{CLINICAL COURSE}

Although only 13 well documented cases of orbital malignant peripheral nerve sheath tumours have been reported, previous authors ${ }^{35}$ have stressed the 


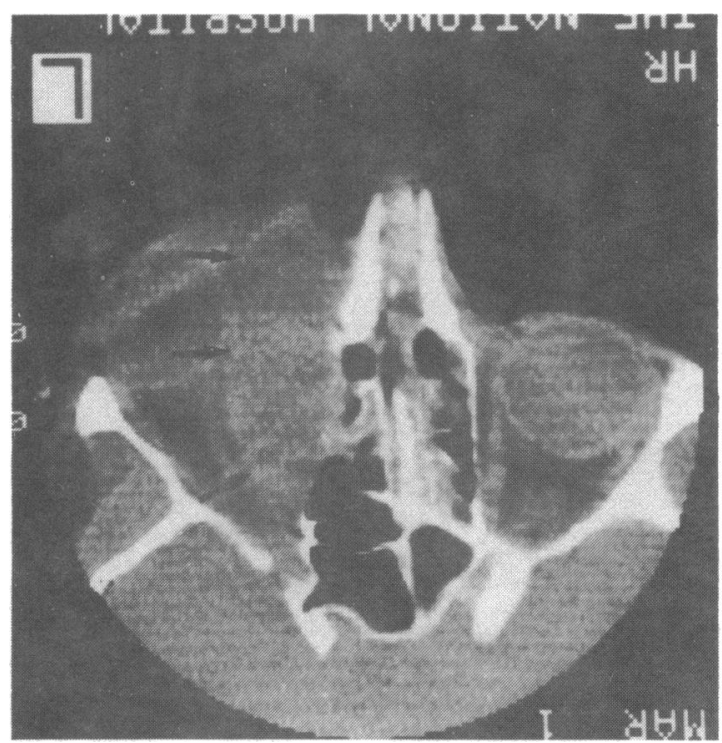

Fig. 7 Patient 3. An axial CT scan shows a large mass (arrows) filling the medial orbit extending from the skin anteriorly almost to the orbital apex. The medial wall of the orbit appeared intact.

tendency for this tumour to arise from the supraorbital branch of the trigeminal nerve (10 cases). Mortada' described an inferotemporal orbital malignant neurilemoma (for which the nerve of origin was not specified), and in our patients the tumour arose from the infraorbital nerve in one and intraconally in another. In the third patient the tumour site was compatible with origin from a medial branch of the ophthalmic division of the trigeminal nerve.

At presentation there is frequently a history of a pre-existing rather innocuous lump, often situated above the medial canthus (as in patient 3), which some patients related to previous trauma $a^{5}$ or which is related to generalised neurofibromatosis (reported in four cases; none of our patients had stigmata of neurofibromatosis). There may have been previous attempts at excision with recurrence after three to nine months (patients 1,3 , and $\mathrm{Schatz}^{2}$ ). The repeated attempts at excision of a benign lesion later complicated by sudden spontaneous enlargement (patient 1) is suggestive of malignant change in a previously benign lesion, as reported by Schatz. ${ }^{2}$

The radiological features of these lesions have not been helpful in establishing or even suggesting the diagnosis. In patient 1 enlargement of the infraorbital canal was suggestive of a nerve tumour, but the circumscribed homogeneous masses seen on CT scans in patients 2 and 3 were non-specific. The hyperaemia of the tumour noted on angiography in patient 2 coupled with the relatively short history suggested the erroneous diagnosis of haemangiopericytoma. Neither of the other cases had such a profuse blood supply.

These tumours behave in an aggressive manner, with extension along the involved nerve into the middle cranial fossa or metastasis to preauricular, submandibular, or cervical lymph nodes ${ }^{5}$ or to distant sites such as lungs and mediastinum (four reported cases) or liver (one reported case). The prognosis is therefore poor. Of 13 cases reported, nine died of their disease within five years. In two further cases follow-up was of nine months or less, and two patients have survived five and seven years respectively.

As peripheral nerve sheath tumours are radioresistant, ${ }^{1011}$ the only treatment capable of producing a cure is total excision. This may be feasible if the lesion is confined within the orbit. Frozen sections may be used to ensure the nerve margins are free of tumour. ${ }^{12}$ However, owing to the tendency of these tumours to spread rapidly along the nerve sheath into the subarachnoid space, ${ }^{8}$ nerve involvement through the superior orbital fissure into the middle cranial fossa is frequently noted at the time or orbital surgery (patients 1,2, and Grinberg and Levy ${ }^{3}$ ). Radical midfacial surgery combined with exploration of the middle cranial fossa then offers the only hope of total excision. Often, as in our first patient, this may not be possible.

Fortunately these tumours are very uncommon, but ophthalmologists should be aware that, when they do occur in the orbit, early diagnosis and extensive surgical intervention may be needed to effect a cure.

A A McNab was supported by a Royal Australian College of Ophthalmologists OPSM travelling fellowship.

\section{References}

1 Mortada A. Solitary orbital malignant neurilemmoma. $\mathrm{Br} J$ Ophthalmol 1968; 52: 188-90.

2 Schatz H. Benign orbital neurilemoma: sarcomatous transformation in von Recklinghausen's disease. Arch Ophthalmol 1971; 86: $268-73$

3 Grinberg MA, Levy NS. Malignant neurilemoma of the supraorbital nerve. Am J Ophthalmol 1974; 78: 489-92.

4 Henderson JW. Orbital tumors. 2nd ed. New York: Decker, 1980.

5 Jakobiec FA, Font RL, Zimmerman LE. Malignant peripheral nerve sheath tumors of the orbit: a clinicopathologic study of eight cases. Trans Am Ophthalmol Soc 1985; 83: 332-66.

6 Stefansson K, Wollman R, Jerkovic M. S-100 protein in soft tissue tumors derived from Schwann cells and melanocytes. Am J Pathol 1982; 106: 261-8.

7 Weiss WS, Langloss JM, Enzinger FM. Value of S-100 in the diagnosis of soft tissue tumors, with particular reference to benign and malignant Schwann cell tumors. Lab Invest 1983; 49: 299-308.

8 Enzinger FM, Weiss SW. Soft tissue tumors. St Louis: Mosby, 1983. 
Fig. 8 Patient 3. (a) The tumour consists of spindle cells distributed in a loose and somewhat haphazard fashion. (Glees and Marsland, $\times 125$ ). (b) In places the cells have unusually large, hyperchromatic nuclei. (Haematoxylin and eosin, $\times 313$ ). (c) Clusters of cells which react positively for $S-100$ protein are extremely sparse.

(Immunoperoxidase, $\times 125$ ).

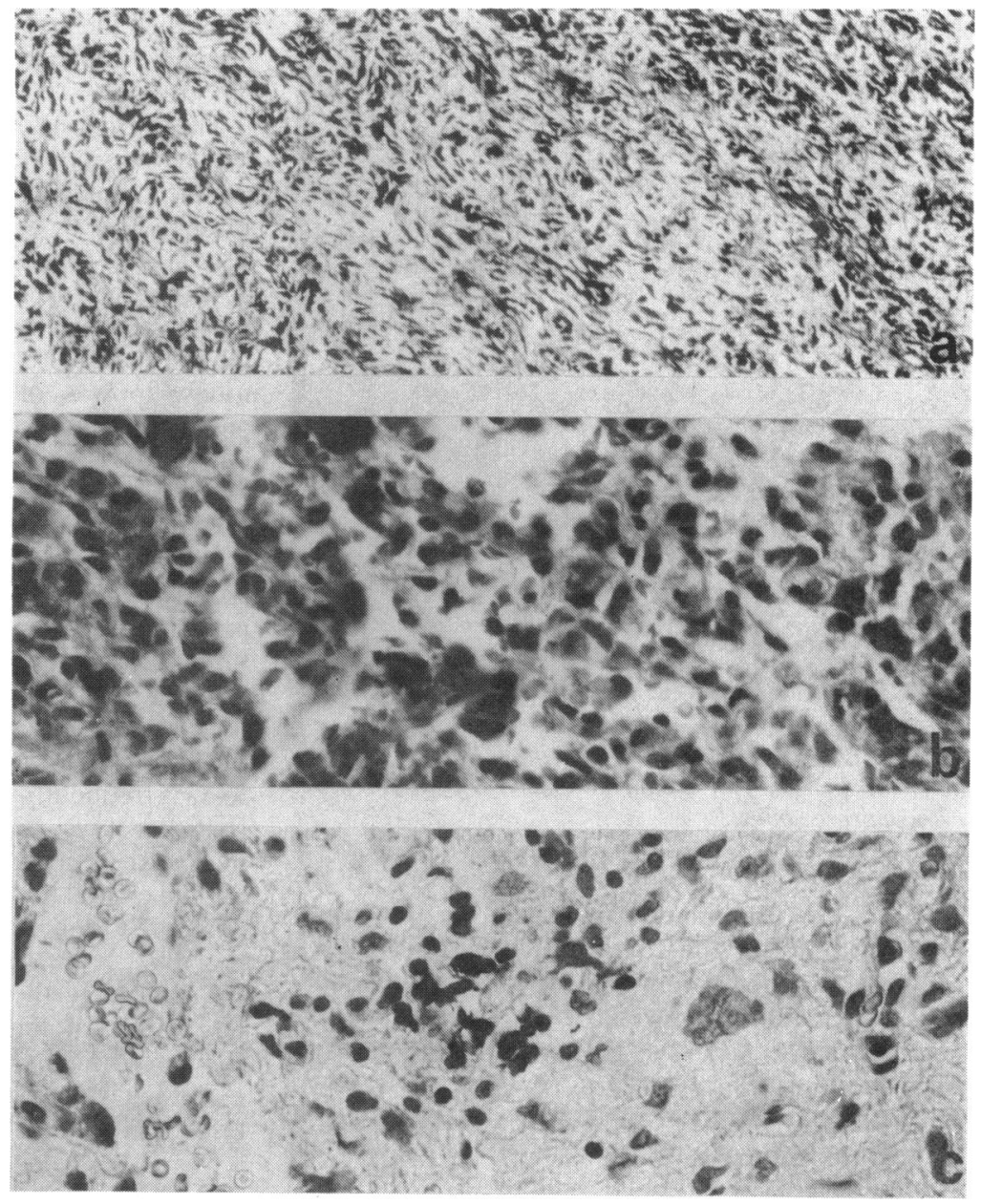

9 Erlandson RA, Woodruff JM. Peripheral nerve sheath tumors; an electron microscopic study of 43 cases. Cancer 1982; 49: 27387

10 Gore DOO, Rankow R, Hanford JM. Para pharyngeal neurilemmoma. Surg Gynecol Obstet 1956; 103: 193-201.

11 Vieta JO, Pack GT. Malignant neurilemmomas of peripheral nerves. Am J Surg 1951: 82: 416-31.

12 D'Agostino AN, Soule SH, Miller RH. Primary malignant neoplasms of nerves. Cancer 1963; 16: 1003-14.

Accepted for publication 9 February 1989. 